\title{
“TINTAS NATURAIS": EXTENSÃO UNIVERSITÁRIA E EDUCAÇÃO AMBIENTAL
}

\author{
Lilian Giacomini Cruz ${ }^{1}$, Camilla da Silva Lima ${ }^{2}$, Gabriela Missae Itihara ${ }^{3}$, Ritielen Maciel \\ Mirandola ${ }^{4}$, Evander dos Santos Sanches ${ }^{5}$, Glaucia Almeida de Morais ${ }^{6}$
}

\begin{abstract}
RESUMO
O presente estudo busca discutir a Educação Ambiental (EA) no ensino superior para além da disciplinarização, elegendo para isso a extensão universitária no seu desenvolvimento. Trata-se de experiências desenvolvidas na Universidade Estadual de Mato Grosso do Sul (UEMS), Unidade de Ivinhema, no âmbito do Programa de Educação Tutorial (PET). As ações planejadas têm sido cumpridas com participação satisfatória do público, colaboradores e das instituições parceiras. Além disso, têm incentivado a autonomia dos graduandos na proposição e execução de propostas, na interação com a comunidade e na busca por embasamento teórico sobre os temas desenvolvidos. Entre as dificuldades encontradas, destaca-se a ainda existente desarticulação entre ensino-pesquisa-extensão.
\end{abstract}

Palavras-chave: Ensino Superior; Ensino-pesquisa-extensão; Socioambiental.

\section{ABSTRACT}

This study discusses the environmental education (EA) in higher education beyond disciplining, electing to this university extension in its development. These are experiences of the State University of Mato Grosso do Sul (UEMS), Unit Ivinhema, under the Tutorial Education Program (PET). The planned actions have been completed with satisfactory participation of the public, employees and partner institutions. Also, they have encouraged the autonomy of the students in proposing and implementing proposals in the interaction with the community and the search for theoretical background on the themes developed. Among the difficulties encountered, there is the still existing disconnection between teaching-research-extension.

Keywords: Higher Education; Teaching-research-extension; Socio-environmental.

\section{INTRODUÇÃO}

Considerando o ensino superior complexo e passível de crítica quanto às funções que desempenha no contexto político-ideológico de desenvolvimento de uma sociedade (OLIVEIRA, 2011), e pelo fato dele assentar-se num tripé (ensino-pesquisa-extensão) que não é exatamente equilibrado, nosso objetivo com o presente estudo é contribuir

\footnotetext{
${ }^{1}$ Doutora em Educação para a Ciência; Docente do Curso de Licenciatura em Ciências Biológicas e do Programa de Pós Graduação em Educação Científica e Matemática (Mestrado Profissional) da Universidade Estadual de Mato Grosso do Sul.

${ }^{2}$ Graduanda do Curso de Bacharelado em Ciências Biológicas.

${ }^{3}$ Graduanda do Curso de Licenciatura em Ciências Biológicas.

${ }^{4}$ Graduanda do Curso de Licenciatura em Ciências Biológicas.

${ }^{5}$ Mestrando do Programa de Pós-graduação em Biologia Animal da UFMS-Campo Grande.

${ }^{6}$ Doutora em Biologia Vegetal; Docente dos Cursos de Licenciatura e Bacharelado em Ciências Biológicas da Universidade Estadual de Mato Grosso do Sul
} 
para o debate a respeito da Educação Ambiental (EA) nas Instituições de Educação Superior (IES) brasileiras, com vistas a uma reflexão sobre políticas públicas educacionais que considerem a Educação Ambiental (EA) na formação dos profissionais de nível superior das diferentes áreas do conhecimento, para além da sua disciplinarização. Trazemos para essa problematização neste artigo as experiências desenvolvidas no âmbito da Extensão, na Universidade Estadual de Mato Grosso do Sul (UEMS), Unidade de Ivinhema.

\section{O PAPEL SECUNDÁRIO DA EXTENSÃO UNIVERSITÁRIA E A NECESSIDADE DE PROTAGONISMO}

Enquanto a universidade é pautada pelo princípio da indissociabilidade entre ensino, pesquisa e extensão, conforme previsto constitucionalmente (BRASIL, 1988), a extensão universitária pode ser definida como "um processo interdisciplinar, educativo, cultural, científico e político que promove a interação transformadora entre universidade e outros setores da sociedade" (FORPROEX, 2012, p.15). Esta definição denota uma postura da universidade que promove uma interação transformadora não apenas de si mesma, mas também de todos os setores sociais com os quais ela interage. Além disso, denota também uma prática acadêmica, a ser desenvolvida de forma indissociável com o ensino e a pesquisa (FORPROEX, 2012).

Para a formulação e implementação das ações de extensão universitária têm sido propostas diretrizes, como a interação dialógica, visando a produção, em interação com a sociedade, de um conhecimento novo que contribua para a superação de problemas, ao invés de simplesmente "estender" à sociedade o conhecimento - as "verdades" acumulado pela Universidade. Considerada desta forma, a diretriz indissociabilidade Ensino - Pesquisa - Extensão parece ter maior efetividade, isto é, as ações de extensão têm mais sentido quando vinculadas ao processo de formação de pessoas (Ensino) e de geração de conhecimento (Pesquisa) (FORPROEX, 2012).

Apesar destes avanços conceituais e teóricos, muito se tem discutido também sobre a necessidade de institucionalização da extensão. Isto é, a necessidade de dar a extensão universitária o mesmo status do ensino e da pesquisa. Nesse sentido, a flexibilização curricular e a integralização de créditos obtidos nas ações de extensão universitária tem criado condições mais objetivas para esse avanço, porém elas não fazem parte da realidade de várias instituições. Na UEMS - Ivinhema, os projetos de 
ensino dos cursos de graduação ainda não têm esta previsão objetiva e as ações extensionistas são validadas no histórico escolar dos alunos como Atividades Complementares.

Diante desta problemática vivenciada por muitas das universidades brasileiras, é preciso uma compreensão mais aprofundada do contexto em que ela está inserida. Para tal, recorreremos a autores que têm discutido a respeito e também proposto algumas possíveis saídas.

A universidade é uma instituição social e, como tal, exprime de maneira determinada a estrutura e o modo de funcionamento da sociedade como um todo. "Tanto é assim que vemos no interior da instituição universitária a presença de opiniões, atitudes e projetos conflitantes que exprimem divisões e contradições da sociedade" (CHAUÍ, 2003, p. 5).

Concordando com as ideias de Chauí (2003), é necessário também explicitar que este modelo no qual a sociedade está inserida é o neoliberal e, que dentro desta perspectiva, alguns setores, como a educação, foram designados como serviços não exclusivos do Estado. Ainda segundo a autora, isto significa dizer que a educação deixou de ser concebida como um direito e passou a ser considerada um serviço e, mais do que isso, deixou de ser considerada um serviço público e passou a ser considerada um serviço que pode ser privado ou privatizado, ou seja, dentro do modelo neoliberal vigente, a universidade é vista como uma organização social e não como uma instituição social.

Para Ferraro Júnior (2011, p. 52), neste contexto, os graves problemas do ensino público fundamental e médio "tornam o acesso à universidade pública uma (quase) prerrogativa das classes sociais que podem custear as boas escolas privadas". Nessa lógica, os profissionais formados pela universidade, os conhecimentos construídos e as intervenções da universidade voltam-se para o mercado, assim como o capital flui para o capital e se concentra progressivamente.

Ainda segundo o autor, este é um problema evidente e difícil de ser resolvido imediatamente. Desta forma, o que se apresenta para esse problema, na maioria das vezes, é uma resposta apressada e simplista, como por exemplo, utilizar-se da extensão como "remendo para a perda de legitimidade da universidade pública brasileira". Neste caso, a universidade cumpriria sua função social por meio da extensão de serviços e 
projetos à população mais pobre, ou seja, numa perspectiva elitista e assistencialista, a extensão tenta remediar as carências generalizadas do Estado de maneira restrita e localizada (FERRARO JÚNIOR, 2011).

Como discute Saviani (1987), é preciso lembrar que a própria palavra extensão traz este significado assistencialista, já que significa estender. Portanto, a ideia que está por detrás é basicamente a seguinte: aqueles que têm, estendem àqueles que não têm. A ideia assistencialista traz, no entanto, uma direção unilateral, quer dizer, é uma espécie de rua de mão única: só vai da universidade para a sociedade. Para que a universidade se insira efetivamente na sociedade de modo consequente, é necessário que se considere a mão inversa também. Com efeito,

[...] é a sociedade que vai colocar os problemas; e é o contato com os problemas efetivos da sociedade que vai permitir à universidade transformar os objetos de suas pesquisas em algo relevante para a sociedade e adequar o ensino às necessidades da sociedade. E é também este contato que vai permitir que se elabore o saber que já está presente na comunidade, que já está presente nas massas, de tal modo que ela seja uma força viva que contribua para a elevação geral do nível de vida desta sociedade (SAVIANI, 1987, p. 55).

Chauí (2003) também nos traz que é necessário estimular as pesquisas a ampliarem sua relevância social e a buscar parcerias com os movimentos sociais para a realização de pesquisas e extensão em via de mão dupla.

Além disso, é necessário abolir a avaliação tecnocrática vigente que se baseia numa perspectiva quantitativa do trabalho docente e da pesquisa, e que deixa de lado a extensão. E ainda, a perspectiva da extensão deve ser assumida como forma de viabilizar "a construção da coesão social, aprofundamento da democracia, luta contra a exclusão social e a degradação ambiental e a defesa da diversidade cultural" (SANTOS, 2005, p. 73).

O importante é que a extensão atinja vários grupos sociais, principalmente os excluídos e discriminados, e evitar a presença de atividades que visem apenas o aspecto econômico a fim de angariar recursos para universidade.

Para a efetiva inclusão das camadas mais desfavorecidas e de outras culturas no ambiente universitário é necessário que o currículo possibilite a presença do diálogo entre o conhecimento científico, produzido pela universidade, e o conhecimento popular, tradicional presente na sociedade. A ecologia dos saberes procura promover o convívio entre esses diversos saberes e estabelece uma nova relação entre sociedade e 


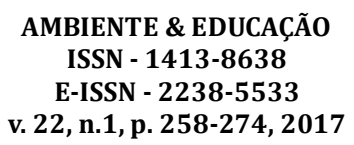

universidade (SANTOS, 2005).

Nesse nível, de acordo com Saviani (1987, p. 61), trata-se, justamente não de se relacionar com a comunidade, com as massas, com o povo, a partir daquele princípio de que nós acadêmicos (docentes e alunos) sabemos tantas coisas e eles ignoram. Mas, sim, a partir do fato de que "sabemos um aspecto da cultura, mas ignoramos muitos outros". E o que sabemos "é um aspecto da cultura que foi elaborado a partir do trabalho da sociedade em seu conjunto".

Os grupos aos quais nos dirigimos, sabem de forma não elaborada e não sistematizada uma porção de coisas sobre as quais não temos conhecimento algum. Eles vivenciam todo um conjunto de problemas e têm uma forma de perceber e de se expressar sobre tais problemas que, quando contraposta à nossa, pode parecer que revela desconhecimento. No entanto, simplesmente, se trata de uma forma diferente, não erudita, contra uma forma elaborada, que acabamos dominando pelo fato de termos percorrido os bancos escolares da educação infantil ao nível superior. Então, nesta postura, trata-se justamente de elaborar este saber de tal modo que não apenas nós o dominemos, mas, sim, contribuindo para que eles próprios também elaborem e expressem este saber (SAVIANI, 1987).

\section{A Educação Ambiental no Ensino Superior}

A preocupação com as questões socioambientais dentro das Instituições de Ensino Superior (IES) no Brasil não é um tema novo, no entanto, a EA ainda vem tentando conquistar esse maior espaço nas atividades de ensino, pesquisa e extensão.

As IES representam importantes espaços para reflexão, formação e difusão de novas concepções de desenvolvimento e sustentabilidade, tendo, portanto, papel fundamental na construção de sociedades mais justas, igualitárias e ambientalmente sustentáveis. Mas, apesar da importância e do potencial das IES para a formação (ensino), pesquisa e extensão, esses contextos ainda permanecem carentes de políticas específicas que apoiem e incentivem o fortalecimento de ações de EA já existentes, além da criação de novos espaços de disseminação de práticas educativas ambientais. Além disso, o meio universitário representa um importante espaço de educação profissional e de formação de futuros professores, o que assume significado da maior importância na sustentação do processo de incorporação da EA nos demais níveis de 
ensino, por meio da formação inicial, continuada e dos programas de pós-graduação e extensão (RUPEA, 2005). Nesse sentido, a EA nos currículos e práticas universitárias possui um sentido estratégico para a incorporação da dimensão ambiental tanto no ensino, como na sociedade.

Do ponto de vista legal, como marco mais recente, temos o estabelecimento das Diretrizes Curriculares Nacionais para a Educação Ambiental (DCNEA), mediante a publicação da Resolução $n^{\circ} 2$ de junho de 2012. Elas reafirmam, em conformidade com a Lei de Diretrizes e Bases da Educação Nacional (BRASIL, 1996) e com a Política Nacional de Educação Ambiental (BRASIL, 1999), que a EA deve estar presente, de forma articulada, nos níveis e modalidades da Educação Básica e da Educação Superior, devendo as instituições de ensino promovê-la integradamente nos seus projetos institucionais e pedagógicos. Entretanto, uma das atuais problemáticas da institucionalização da EA concerne à necessidade de torná-la parte da formação dos profissionais de nível superior.

Em 2004/2005 a Rede Universitária de Programas de Educação Ambiental para Sociedades Sustentáveis (RUPEA) realizou um mapeamento que envolveu um conjunto de instituições brasileiras de ensino superior sobre a inserção da temática ambiental e o desenvolvimento de uma cultura ambiental nas universidades brasileiras, bem como a definição de critérios mínimos para a formulação de políticas públicas para este setor. Dentre os principais resultados obtidos pelo estudo realizado, destaca-se o fato de que, em uma amostra de 27 universidades brasileiras, públicas e privadas, distribuídas em 11 estados, apenas $13(48 \%)$ apresentavam políticas e/ou programas institucionais de educação ambiental. Além disso, o estudo também observou que, embora a temática ambiental tenha irrompido nas políticas públicas voltadas à normatização dos mais diversos setores sociais e institucionais, como o da educação básica, o setor acadêmico ainda carece de diretrizes para a implementação da EA em todas as suas atividades.

Diante disso, de acordo com Tozoni-Reis (2012, p.276), parece importante que "a inserção da EA nas escolas de todos os níveis" se dê pelo currículo, compreendendoa como uma atividade nuclear da forma como discutiu Saviani (2005). No entanto, sabemos que essa inserção pelos currículos é um tema "delicado" para a EA, em cujas práticas podemos identificar uma tendência em desvalorizar o currículo como possibilidade concreta da realização de práticas críticas e reflexivas. Isso parece indicar 


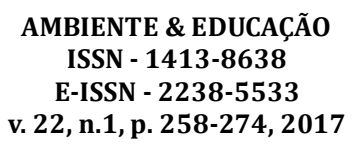

que a única forma de inserção curricular é a forma disciplinar. No entanto, inserir no currículo não significa, necessariamente, criar uma disciplina específica, mas fazer com que a EA participe como atividade nuclear do currículo (TOZONI-REIS, 2012), o que nos remete à ideia de que ela deve ser trabalhada como conteúdo das diferentes disciplinas. Conteúdo este que emerge da prática social em que professor e aluno estão inseridos, consolidando-se num processo que permite ao aluno tomar posse dos “instrumentos teóricos e práticos necessários ao equacionamento dos problemas detectados na prática social” (SAVIANI, 2008, p. 71), ferramentas culturais que possibilitam às camadas populares lutarem pela superação das condições de opressão em que vivem.

A esse respeito, Riojas (2003 apud OLIVEIRA, 2011, p. 39) nos traz uma importante contribuição: diante da complexidade das questões ambientais - refletida pelas suas interfaces e articulação no âmbito conceitual, teórico, pedagógico, institucional e existencial, a educação superior depara-se com "um dos desafios potencialmente mais revolucionários para as próximas décadas", especialmente se considerarmos a natureza ambivalente das IES, onde convivem o pensamento livre e criativo e, ao mesmo tempo, as amarras que impedem sua autonomia.

Segundo Oliveira (2007), esse processo pode ser melhor compreendido se levarmos em conta a evolução das IES, pautada na simplificação, fragmentação e especialização do conhecimento e na dependência que estas apresentam de agentes externos, sejam eles político-ideológicos (governos), sejam econômicos (o mercado) e que são condicionamentos históricos e constitucionais.

Leff (2002, p. 161) também discute este processo denominando-o de “internalização da dimensão ambiental”. Para o autor, o que a problemática ambiental propõe às ciências - quanto à produção de conhecimentos - e às universidades - quanto à formação de recursos humanos - transcende a criação de um espaço acadêmico formado pela integração das disciplinas tradicionais ou da geração de um campo homogêneo e totalizador das "ciências ambientais", de valor universal. E ainda:

A incorporação do saber ambiental nas práticas científicas e docentes vai além de um requerimento de atualização dos currículos universitários a partir da internalização de uma "dimensão" ambiental generalizável aos diferentes paradigmas do conhecimento. $\mathrm{O}$ saber ambiental não emerge de uma reorganização sistêmica dos conhecimentos atuais. Este se gesta por meio da transformação de um conjunto de paradigmas do conhecimento e de formação ideológicas, a partir de uma problemática social que os questiona e 
os ultrapassa (LEFF, 2002, p. 163).

Não há dúvida de que há um consenso em torno da importância de se encontrar caminhos para consolidar a inserção da dimensão ambiental de maneira mais efetiva nos processos formativos, principalmente nas IES. No entanto, a abertura dos campos disciplinares a uma perspectiva ambiental e a sistematização de um saber ambiental, tal como nos coloca Leff (2002), que possa ser incorporado às práticas acadêmicas, requer, em última análise, a reformulação dos conhecimentos dos docentes e a expansão de uma nova cultura, processos que implicam medidas institucionais voltadas à criação de novos espaços acadêmicos que favoreçam relações dialógicas e interdisciplinares (RUPEA, 2005).

Para González-Gaudiano (2005) não houve até o momento um debate apropriado para dar a especificidade requerida a um campo que se reconhece como de convergência disciplinar de áreas em conflito epistemológico e socioprofissional - as ciências naturais e as ciências sociais. A perspectiva da não-disciplina já estava prevista no informe da Conferência de Tbilisi, em 1977, mas no corpo do documento gerado, não há muitas referências sobre a interdisciplinaridade.

Ainda segundo o autor, há dificuldade na integração de métodos e conceitos de diversas disciplinas, mais fácil de ser estabelecida em termos conceituais que em termos operacionais, o que de fato reflete a realidade da inserção da EA no contexto escolar, em qualquer nível.

Para Tozoni-Reis (2001), interdisciplinaridade não significa apenas a articulação formal entre as disciplinas existentes atualmente, mas exige uma definição paradigmática:

A universidade, para o enfrentamento dos desafios sociais e políticos que hoje estão a ela colocados, precisa enfrentar desafios paradigmáticos de transformação estrutural profunda, terá que transformar o ensino, a pesquisa e a extensão pela construção radical da totalidade (TOZONI-REIS, 2001, p. 49).

Nesse sentido, a formação a ser oferecida pelas IES, será pontuada pela ideia de que o ambiente é cada vez mais, se considerarmos todo movimento de arranjos no capitalismo internacional, um fenômeno social. Estudar a natureza é, cada vez mais, tomar decisões histórico-científicas sobre a relação homem-natureza (TOZONI-REIS, 2001). 


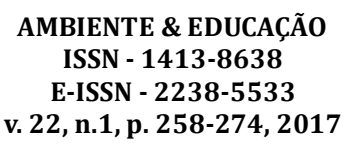

Ainda segundo a autora, o paradigma da totalidade histórica possibilita a interdisciplinaridade e, nesse sentido, as ciências ambientais apresentam-se como espaço acadêmico e científico privilegiado das transformações, porque são paradigmáticos quando pensamos em transformações das formas de conceber e fazer a ciência e a sociedade.

\section{COMO INCORPORAR A EA NOS CURSOS DE FORMAÇÃO PARA ALÉM DA DISCIPLINARIZAÇÃO?: A EXTENSÃO E AS PRÁTICAS EDUCATIVAS SOCIOAMBIENTAIS DA UEMS-IVINHEMA}

Para Ferraro Júnior (2011, p. 53), independente de seus benefícios sociais, na universidade a extensão tem como função integrar pesquisa e ensino, para "aterrizar a universidade na realidade da nossa sociedade". E ainda:

O florescimento da extensão na universidade pública não resolve o problema da elitização do acesso a ela, mas certamente pode melhorar a relação entre a sociedade (e não apenas seus filhos diletos) e a universidade, além de aproximá-las. Desenvolver pesquisa e ensino com base na extensão pode não garantir, mas é um passo enorme para aumentar a significação e a qualidade dos mesmos.

E, como incorporar a dimensão ambiental na Extensão?

Para Tonso (2011, p.68), toda atividade: que traga a dimensão complexa das questões contemporâneas (nas quais o social e o ecológico não são dissociados, reconhecendo-se o socioambiental); que se realize no diálogo horizontal entre a universidade e a comunidade não universitária; em que o princípio da inclusão não hierárquica de diferentes saberes, pontos de vista e visões de mundo se realizem como princípio político-metodológico; que busque compreender as causas das questões e sobre esta compreensão paute suas ações de transformação; que reconheça e valorize o papel do indivíduo em constante diálogo com a coletividade a que pertence, pode ser chamada de uma "ação de extensão universitária ambientalizada".

A fim de problematizar a questão do papel da extensão no processo de inserção da EA no ensino superior, para além da disciplinarização, trazemos algumas experiências dos cursos de Licenciatura e Bacharelado em Ciências Biológicas da UEMS, Unidade de Ivinhema.

Em 2010, o Conselho Federal de Biologia (CFBio) publicou a Resolução no 213, de 20 de março, estabelecendo os requisitos mínimos para o biólogo atuar em pesquisa, projetos, análises, perícias, fiscalização, emissão de laudos, pareceres e outros serviços nas áreas de meio ambiente, saúde e biotecnologia, conforme especificado no Parecer 
do Grupo de Trabalho (GT) Revisão das Áreas de Atuação/CFBio 01/2010. Para os cursos de bacharelado, na área de Meio Ambiente, entre as sugestões de disciplinas o GT cita "Educação e Interpretação Ambiental", a qual foi acatada durante a elaboração do projeto pedagógico do curso de Bacharelado em Ciências Biológicas, da UEMS Ivinhema, em 2012. Apesar disso, na reformulação do projeto pedagógico do curso de Licenciatura em Ciências Biológicas, também em 2012, não houve a inclusão da mesma disciplina, nem mesmo a indicação de alguma flexibilização curricular para a inclusão de atividades extensionistas nos créditos exigidos na formação acadêmica.

A iniciativa de se incluir uma disciplina de EA no curso de Bacharelado em Ciências Biológicas, naquele momento, ocorreu de forma a atender uma reivindicação do CFBio que era específica para a formação do(a) biólogo(a), e não para dar início a um processo de incorporação da dimensão ambiental no currículo, o que também justifica o fato desta disciplina não ser oferecida à Licenciatura.

No entanto, sabemos que a simples adoção de uma disciplina no currículo de graduação não garante o cumprimento dos objetivos das políticas públicas no que diz respeito à inserção da EA nos diferentes níveis de ensino, nem permite à universidade afirmar que possui um currículo "ambientalizado". Além disso, também sabemos que sem a articulação efetiva entre ensino-pesquisa-extensão, conforme discutido anteriormente, dificilmente conseguiremos avançar. Por outro lado, consideramos também a importância em dar maior visibilidade às ações de extensão que, mesmo de forma isolada, tentam iniciar este difícil processo, como por exemplo por meio das ações desenvolvidas pelo Programa de Educação Tutorial (PET).

Oficialmente instituído no âmbito do Ministério da Educação (MEC) em 2005, o PET é desenvolvido por grupos de estudantes de graduação, com tutoria de um docente, nas Instituições de Ensino Superior (IES) do país, também orientados pelo princípio da indissociabilidade entre ensino, pesquisa e extensão e da educação tutorial.

Na UEMS, em Ivinhema-MS, o Grupo PET Verde Legal existe desde dezembro de 2010, vinculado aos cursos de Licenciatura e de Bacharelado em Ciências Biológicas e Tecnologia em Horticultura (desativado). O objetivo principal desse Grupo é capacitar graduandos para atuarem na recomposição da vegetação nativa da região. Visando alcançar este objetivo, seus integrantes têm se deparado com questões culturais arraigadas em comportamentos ambientalmente inadequados para a sustentabilidade 


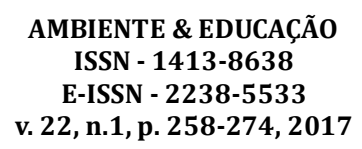

ambiental. A paisagem da região, que até meados da década de 1960 era pouco afetada, devido à ação do homem, seja pela pecuária extensiva, seja pelo crescimento da agricultura mecanizada, passou por grandes modificações, com alteração de diversos habitats e, consequentemente, ameaçando a sobrevivência de muitas espécies.

Diante desta constatação, o grupo tem lançado mão de ações educativas voltadas para a comunidade externa à instituição, no sentido de promover a reflexão e a mudança de atitude frente às questões ambientais.

Entende-se que a EA não-formal definida como "as ações e práticas educativas voltadas à sensibilização da coletividade sobre as questões ambientais e à sua organização e participação na defesa da qualidade do meio ambiente" (PNEA - Lei no 9.795/99) pode ser operacionalizada no âmbito institucional via extensão universitária, a qual, "além de instrumentalizadora desse processo dialético de teoria/prática/ reflexão/prática, [...] é um trabalho interdisciplinar que favorece a visão integrada de todas as dimensões da sociedade" (RESOLUÇÃO COUNI-UEMS No 289, de 9 de novembro de 2005).

Desde a sua inclusão no programa do MEC, o PET Verde Legal tem focado suas atividades na produção de mudas de espécies nativas, o que implica em coleta, beneficiamento e semeadura de diásporos regularmente, preparo de substratos e condução das mudas em viveiro até o momento de envio das mudas para os plantios, conduzidos pelo próprio grupo ou por proprietários rurais que recebem as mudas sem custo algum, como forma de incentivo à recomposição vegetal de suas propriedades, especialmente de áreas de preservação permanente e de reserva legal. Além desta atividade regular do grupo, os integrantes organizam e realizam esporadicamente diferentes ações, voltadas para a sensibilização da comunidade interna e externa sobre a temática ambiental, como campanhas de coleta de lixo eletrônico e pelo consumo consciente, promoção de concurso de projetos ecossustentáveis, colônias de férias ecológicas, entre outras.

\section{Projeto Tintas Naturais}

O Projeto Tintas Naturais em análise, foi desenvolvido no Projeto Sagrado Coração no município de Ivinhema-MS, uma instituição filantrópica de caráter cultural, assistencial e educacional, sem fins lucrativos, que visa apoiar o desenvolvimento físico 
ISSN- 1413-8638

E-ISSN - 2238-5533

v. 22, n. 1, p. 258-274, 2017

e intelectual de crianças e adolescentes de 7 a 16 anos, sendo mantida pela Associação Missionária Catequista do Sagrado Coração do município.

Tintas naturais são aquelas feitas de elementos da natureza, ou seja, a partir de compostos orgânicos como cascas, raízes, frutos, aparas de madeira, folhas, flores, insetos, terra, entre outros. A variedade é tão grande que, somente no grupo dos vegetais, pode-se obter mais de 500 cores. Além disso, qualquer tipo de terra pode ser utilizado para fazer tinta, a escolha vai depender da cor e do efeito que se busca. Estas tintas podem ser utilizadas para tingir tecido e papel, corar alimentos ou até cosméticos (CONSCIÊNCIA AMPLA, 2013).

As tintas naturais são utilizadas pela humanidade há mais de 5.000 anos, com o começo ainda na era neolítica. Corantes derivados da planta Isatis tinctoria vieram mais tarde, durante a Idade do Bronze. Os egípcios introduziram raiz de açafrão, cúrcuma e índigo (extraído da planta Indigofera tinctoria, de coloração azul). No final de 1700, os italianos começaram a substituir os corantes naturais por produtos químicos. Em 1856, a indústria química criou o primeiro corante sintético e, a partir daí, muitas pesquisas foram desenvolvidas e cada vez mais os corantes artificiais passaram a ocupar o lugar dos naturais. Na metade do século XX surge a tinta acrílica. Nos laboratórios, novas cores continuam a ser descobertas e criadas, como as tintas fosforescentes. Na década de 1980 havia 3 milhões de cores disponíveis. Desde então, o homem vem utilizando indiscriminadamente estes corantes químicos para diversas finalidades. Na década de 1990, Estados Unidos, França e Inglaterra proíbem o uso de corantes químicos nas indústrias de alimentos e cosméticos (ECODESENVOLVIMENTO, 2012).

Muitas das tintas industrializadas, utilizadas convencionalmente, contêm metais pesados que podem gerar problemas de saúde para as pessoas que as produzem e depois, para o ambiente, contaminando o solo. O uso de produtos naturais reduz a emissão de efluentes químicos - corantes sintéticos e produtos auxiliares nocivos melhorando a qualidade de vida e atendendo a crescente demanda de produtos fabricados de acordo com as normas e conceitos de preservação ambiental e responsabilidade social. Além disso, as tintas naturais são mais baratas, quando feitas artesanalmente, promovem o resgate de costumes ancestrais, não provocam alergias e nem possuem odor.

Trazendo esta proposta e pensamento para a educação, Santos (2013) destaca 
que a produção artesanal destas tintas é simples e divertida, bastando misturar água e cola branca a um ingrediente natural. Segundo a autora, "ao preparar a tinta, os alunos aprendem que não existem apenas produtos industrializados". Acrescenta ainda que os alunos podem pesquisar substâncias corantes, buscando outras opções de cores e estimulando a participação na atividade proposta.

As ações desenvolvidas pelo grupo PET Verde Legal visaram contribuir para uma mudança na forma com o que os participantes veem a natureza, marcada pela degradação do meio ambiente, especialmente combatendo o consumismo. Procurou-se promover também um maior esclarecimento das crianças e adolescentes atendidos pelo Projeto Sagrado Coração sobre as questões ambientais, atentando para o desenvolvimento de uma percepção crítica sobre o consumo exagerado de produtos industrializados. As atividades foram realizadas em encontros que ocorreram nos meses de abril e maio de 2014. A programação do evento contou com: palestra introduzindo o tema "Tintas Naturais", complementada com a exibição de vídeos; oficinas para a produção das tintas, confecção e personalização de sacolas ecológicas, customização de capas de agendas escolares com materiais recicláveis, customização de roupas com muito tempo de uso, pintura de quadros (telas de material reciclável), pintura de azulejos etc.

Enquanto as atividades voltadas para a temática ambiental são normalmente trabalhadas em datas específicas do calendário escolar, explicitamente aquelas relacionadas à água, árvore, meio ambiente, as atividades do Projeto Tintas Naturais foram planejadas pelos integrantes do grupo e procuraram associar a data do "Dia das Mães”, normalmente trabalhada com apelo emocional pela escola e com apelo comercial pela mídia, a um momento oportuno para sensibilizar as crianças e adolescentes atendidos no projeto para o consumo consciente e sustentável. Lembranças e cartões foram confeccionados por eles mesmos com o uso de tintas produzidas basicamente a partir de materiais vegetais. Para finalizar a programação, os participantes vieram à Universidade e conheceram mais sobre os estudos que são feitos na instituição, as coleções de material botânico e zoológico disponíveis, ampliando a noção que tinham sobre a diversidade de organismos e sobre a responsabilidade dos seres humanos sobre a sua preservação. 


\section{FACILIDADES E DIFICULDADES ENCONTRADAS}

Com relação à inserção da EA no ensino superior, apontamos como uma das maiores dificuldades encontradas neste início do processo, a ainda existente desarticulação entre ensino-pesquisa-extensão. Acreditamos que a articulação da extensão com o ensino e com a pesquisa é de grande importância na incorporação da dimensão ambiental na formação profissional, na medida em que se apoia fortemente no diálogo com a comunidade com o propósito de compreender suas linguagens, valores e necessidades. No entanto, como já discutimos anteriormente, nas universidades de forma geral, a valorização das atividades de extensão, em relação àquelas de pesquisa e ensino, é o grande desafio.

As atividades extensionistas por nós planejadas têm sido cumpridas com participação satisfatória do público, colaboradores e das instituições parceiras. Por outro lado, as ações têm sido pontuais e despertam maior interesse dos participantes (principalmente de estudantes do Ensino Fundamental e Médio) pelo aspecto de "sair da rotina", mas entende-se que, embora exista a expectativa de que as ações tenham contribuído para uma maior reflexão dos participantes sobre as questões abordadas, a falta de continuidade destas ações também resulta em incertezas sobre estes mesmos pontos.

Do ponto de vista da formação acadêmica, as ações extensionistas têm incentivado a autonomia dos graduandos na proposição e execução de propostas, na interação com a comunidade não universitária e na busca de embasamento teórico por meio de pesquisa sobre os temas desenvolvidos nestas ações. Entretanto, por não fazerem parte do currículo obrigatório dos cursos, muitos alunos concluem seus cursos sem nunca terem participado da extensão enquanto graduandos.

Há ainda que se considerar que o PET, assim como outros programas que oferecem bolsas, tem um número limitado de integrantes, não abrangendo a totalidade dos acadêmicos de um curso.

\section{CONSIDERAÇÕES FINAIS}

Ao longo da nossa trajetória, temos nos convencido do grande potencial da ação pedagógica ambiental, desenvolvida no âmbito do programa PET, como propositora de 
mudanças. No entanto, também estamos convencidos de que esta ação necessita ser fortalecida e, que o grupo possui muitos desafios para o aperfeiçoamento de seu trabalho, tais como, uma maior fundamentação teórica para a elaboração de suas práticas educacionais e a incorporação mais intensa da diversidade de saberes necessária para a formação de um pensamento crítico. Porém, a dinâmica de trabalho dentro do projeto oferece um grande potencial para a superação desses desafios.

Compartilhamos a ideia de que a criação de espaços reflexivos e democráticos nas universidades, onde a troca de saberes e a colaboração são praticadas e incentivadas, permite avançar na direção dos valores conectados à perspectiva da sustentabilidade socioambiental, distanciando-nos dos procedimentos centralizadores e das estruturas autoritárias e competitivas existentes (OLIVEIRA, 2011).

Com relação à falta de continuidade e de acompanhamento posterior das ações desenvolvidas pelo grupo, acreditamos que seria interessante desenvolver nossas ações sob a perspectiva da pesquisa-ação, mais indicada para os projetos que envolvem a comunidade e organizações populares na definição e organização de seus problemas.

A articulação entre a extensão e a pesquisa-ação no ensino superior, é, segundo nossas reflexões, de grande potencial para que a extensão possa ser colocada no mesmo nível do ensino e da pesquisa; não como o "pé atrofiado do tripé", que se faz quando aparece uma oportunidade, mas, ao contrário, como uma atividade robusta, participativa e contínua de formação inicial dos alunos nos cursos de graduação e de formação continuada dos professores que atuam nestes cursos.

A EA trabalhada no âmbito da extensão só poderá atingir uma importância e/ou uma função equiparada às outras atividades universitárias (ensino e pesquisa), na medida em que elas se articulem e na medida em que o próprio ensino aborde tais questões (de forma interdisciplinar) e seja visto, também, como uma forma de aproximação dos problemas da sociedade em seu conjunto. Além disso, na medida em que a própria pesquisa seja vista desta forma, ela irá explorar problemas como os socioambientais, que são candentes à sociedade em que ela está inserida.

\section{REFERÊNCIAS}

BRASIL. Constituição da República Federativa do Brasil. Brasília, DF: Senado Federal, 1988. $292 \mathrm{p}$.

. Política Nacional de Educação Ambiental. Lei n. ${ }^{\circ}$ 9.795, 27 de abril de 1999. 
. Lei de Diretrizes e Bases da Educação Nacional: no 9394/96. Brasília: 1996.

CHAUÍ, M. A universidade pública sob nova perspectiva. Revista Brasileira de Educação, dez, n. 24, p. 5-15, 2003.

CFBio - Conselho Federal de Biologia. Resolução no. 213, de 20 de março de 2010. Brasília, DF: Imprensa Nacional, n. 56, DOU de 24/03/10 - seção 1 - p. 100.

CONSCIÊNCIA AMPLA. A cor da natureza: aprenda a fazer uma tinta natural. 2013. Disponível em: http://www.revistaamazonia.com.br/meio-ambiente/1150-a-cor-da-naturezaaprenda-a-fazer-uma-tinta-natural-com-talos-frutos-e-flores-. Acesso em 20 mar. 14.

ECODESENVOLVIMENTO. EcoD Básico: Tintas naturais. Disponível em: http://www.ecodesenvolvimento.org/posts/2012/agosto/ecod-basico-tintasnaturais\#ixzz4DAJYkFrx. Acesso em 20 mai. 2014.

FERRARO JÚNIOR, L.A. A sustentabilidade na extensão universitária. In: LEME, P.C.S.; PAVESI, A.; ALBA, D.; GONZÁLEZ, M.J.D. (Org.). Visões e experiência ibero-americanas de sustentabilidade nas universidades: desdobramentos do $3^{\circ}$ Seminário Internacional de Sustentabilidade na Universidade, São Carlos, 2011, p. 51-57.

FORPROEX - Fórum de Pró-Reitores de Extensão das Universidades Públicas Brasileiras. Política Nacional de Extensão Universitária. Manaus, 2012. Disponível em: http://www.renex.org.br/documentos/2012-07-13-Politica-Nacional-de-Extensao.pdf Acesso em: 04 mar. 2015.

GONZALEZ-GAUDIANO, E. Interdisciplinaridade e educação ambiental: explorando novos territórios epistêmicos. In SATO, M.; CARVALHO, I.C.M. Educação Ambiental: pesquisa e desafios. São Paulo: Artmed Editora, 2005, p.119-133.

LEFF, E. Epistemologia ambiental. 2. ed. São Paulo: Cortez, 2002.

OLIVEIRA, H.T. La formación ambiental en la educación superior: creatividad y autonomia entre amarras y resistencias, In: GONZÁLEZ-GAUDIANO, E. (Org.) La educación frente al desafío ambiental global: una visión latinoamericana, Plaza y Valdés, México, D.F., p. 145$158,2007$.

Contextos e desafios na produção de sentidos sobre sustentabilidade e ambientalização da educação superior. In: LEME, P.C.S.; PAVESI, A.; ALBA, D.; GONZÁLEZ, M.J.D. (Org.). Visões e experiência ibero-americanas de sustentabilidade nas universidades: desdobramentos do $3^{\circ}$ Seminário Internacional de Sustentabilidade na Universidade, São Carlos, 2011, p. 37-41.

RESOLUÇÃO COUNI-UEMS $\mathrm{N}^{\circ}$ 289, de 9 de novembro de 2005. Disponível em: http://www.uems.br/portal/ailen/repositorio/2010-11-24_14-16-55.pdf .Acesso em: 12 mar. 2015.

RUPEA. Rede Universitária de Programas de Educação Ambiental para Sociedades Sustentáveis. Mapeamento da Educação Ambiental em instituições brasileiras de Educação Programas de Educação Ambiental para Superior: elementos para discussão sobre políticas públicas. Relatório Sociedades Sustentáveis. (2005). Técnico. Coordenação: Oliveira, H.T. 134 p. + anexos.

SANTOS, B.S. A universidade do século XXI: para uma reforma democrática e emancipatória da universidade, Cortez, São Paulo, 2005.

SANTOS, R. Como fazer tintas naturais. Disponível em: http://criatividadeeciencia.blogspot.com.br/2013/03/tintas-naturais-como-fazer-professora.html. Acesso em: 20 mar. 14 


$$
\begin{gathered}
\text { AMBIENTE \& EDUCAÇÃO } \\
\text { ISSN - 1413-8638 } \\
\text { E-ISSN - 2238-5533 } \\
\text { v. 22, n.1, p. 258-274, } 2017
\end{gathered}
$$

SAVIANI, D. Extensão Universitária: uma abordagem não extensionista. In: Ensino público e outras falas sobre universidade. São Paulo: Cortez/Autores Associados, 1987.

Pedagogia Histórico-Crítica: primeiras aproximações. 9. ed. Campinas: Autores Associados, 2005.

Escola e democracia (edição comemorativa). Campinas: Autores Associados, 2008.

TONSO, S. A ambientalização da universidade e a extensão universitária. In: In: LEME, P.C.S.; PAVESI, A.; ALBA, D.; GONZÁLEZ, M.J.D. (Org.). Visões e experiência iberoamericanas de sustentabilidade nas universidades: desdobramentos do $3^{\circ}$ Seminário Internacional de Sustentabilidade na Universidade, São Carlos, 2011, p. 65-70.

TOZONI-REIS, M.F.C. Educação Ambiental: referências teóricas no ensino superior. Interface _ Comunic, Saúde, Educ, v.5, n.9, p.33-50, 2001.

Educação Ambiental na escola básica: reflexões sobre a prática dos professores. Revista Contemporânea de Educação, vol. 7, n. 14, agosto/dezembro, 2012. 